2ND International Conference on Applied Research in

ENGINEERING, SCIENCE AND TECHNOLOGY

5 - 7 JUNE, 2019

BRUSSELS, BELGIUM

\title{
An Experimental Study on the Heat Transfer Characteristics of a Radiant Cooled Floor
}

\author{
Yakup Karakoyun ${ }^{1,}$, Ozgen Acikgoz ${ }^{2}$, Zehra Yumurtaci ${ }^{1}$, Ahmet Selim Dalkilic², \\ Berkay Acar ${ }^{2}$ \\ ${ }^{a}$ Energy Division, Department of Mechanical Engineering, Yildiz Technical University, Turkey \\ ${ }^{b}$ Heat and Thermodynamics Div., Department of Mechanical Engineering, Yildiz Technical University, Turkey \\ *Corresponding author: yakupkarakoyun@gmail.com
}

\begin{abstract}
Radiant heating/cooling systems are being important and preferable due to their extensive usage area and energy saving status. Many kinds of energy generation systems can be utilized to supply energy for heating systems, such as renewable energy systems. As a result of these advantages, research over radiant heating and cooling in various sub-areas have remarkably increased in last decades, particularly with regard to obtaining the most suitable heat transfer characteristics for the use in building simulation programs, dimensioning, and designing. This study presents the heat transfer characteristics over a radiant cooled floor under the experimental conditions as of 3 different supply water temperatures of $10^{\circ} \mathrm{C}, 15^{\circ} \mathrm{C}$, and $20^{\circ} \mathrm{C}$ with supply water flow rates as 0.056 and $0,125 \mathrm{~kg} / \mathrm{s}$. The experimental results are compared with relevant literature and heat transfer coefficients are recommended.
\end{abstract}

Keywords: radiant heating/cooling, floor cooling, heat transfer characteristics

\section{Introduction}

Radiant heating and cooling systems are the preferable air conditioning systems due to their advantages such as providing a homogeneous heat distribution, cooperation with supplementary systems including solar systems and heat pumps, and no extra need for mechanical equipment in the conditioned area, etc. Therefore, determining the heat transfer characteristics of a radiant heating/cooling system is the most important step in dimensioning, designing, and determining thermal capacity. In the literature, it is seen that various studies have been conducted on radiant heating and cooling systems and in the following paragraphs the short summaries of floor cooling systems is given. 
Applying radiant floor systems in places having wide floor surfaces is a prevalently investigated issue. Zhao et al. [1] have studied the working conditions of a floor cooling system implemented in Xi' an Xianyang International Airport, China. According to their analyses, it is found that in summer season, the capacity of radiant floor cooling system is between 30 and 40 $\mathrm{W} / \mathrm{m}^{2}$, where mean temperature of water is $18{ }^{\circ} \mathrm{C}$. In the case that solar radiation effect on radiant floor cooling is present, the range of cooling capacity reaches to $110-140 \mathrm{~W} / \mathrm{m}^{2}$. Evaluation values are recorded in the time period of July 8-22, 2013, which is the warmest time interval of summer season. In addition, authors indicate that the radiant floor heating/cooling systems can provide a more comfortable living environment to occupants, especially in cooling mode. In another study by same authors (Zhao et al., 2013) they suggest that radiant floor cooling can be implemented in large enclosures having high solar radiation. According to the study a practical technique is offered to calculate and determine the performance of radiant floor cooling systems subjected to intense solar radiation. Study reveals that cooling capacity of selected floor cooling application can be specified in the interval of $50-100 \mathrm{~W} / \mathrm{m}^{2}$. The authors compare the floor cooling system with air-jet ventilation regarding with the thermal comfort and energy efficiency, and radiant floor cooling systems show better results as one of their conclusions. Besides these results, the presence of furniture in space has also been analyzed. With as similar approach, Pantelic et al. [3] investigate the effect of solar radiation on floor cooling capacity of a full scale laboratory at various supply water temperatures. In their experimental study, while determining the cooling capacity of the test chamber, the effects of direct solar radiation, air movement due to fan, and carpet are evaluated. As a result of the work, it is found that the floor cooling capacity varies between 32 and $110 \mathrm{~W} / \mathrm{m}^{2}$ for direct solar radiation with the highest surface temperature of $26^{\circ} \mathrm{C}$ with respect to parts of floor $\left(20-21{ }^{\circ} \mathrm{C}\right)$ which has no solar radiation exposure. As it is expected, cooling capacity of radiant floor system decreases with the increase of supply water temperature. In the study authors express one limitation of the work as that the solar radiation affecting floor area to be small due to the season. This situation is necessary to be paid attention in the evaluation of results.

In determining the heat transfer characteristics of a radiant system, the heat transfer coefficients have crucial role. Thus, Olesen et al. [4] present a study related to this issue. In their work, the heat transfer coefficients (total, convective, and radiative) for a hydronic radiant floor cooling system have been theoretically and experimentally studied. Experiments are conducted using a $6 \mathrm{~m}$ by $4 \mathrm{~m}$ by $2.8 \mathrm{~m}$ area which is enclosed by an external chamber. According to the results, selected reference temperature in calculation process have had an important role on heat transfer coefficients. It is concluded for a radiant floor cooling system that if heat transfer mechanisms are defined individually, convective and radiative heat transfer coefficients are recommended as $1.0 \mathrm{~W} / \mathrm{m}^{2} \mathrm{~K}$, and $5.5 \mathrm{~W} / \mathrm{m}^{2} \mathrm{~K}$ (also in EN 15377-1 [5]), respectively. In addition, the temperature differences are selected as temperature difference 
between floor surface and air temperature, and difference between floor surface and surrounding temperature for convective and radiative heat exchange, respectively. However, while determining the total heat exchange, which indicates the combine effect of radiative and convective heat transfer, the temperature difference is suggested as difference between operative and floor surface temperatures along with a total heat transfer coefficient recommendation of $7.5 \mathrm{~W} / \mathrm{m}^{2} \mathrm{~K}$.

Cholewa et al. [6] conduct an experimental work on radiant floor heating/cooling system. So as to characterize the heat transfer mechanism of the radiant floor system, a $1.56 \mathrm{~m}$ by $1.56 \mathrm{~m}$ by $2.21 \mathrm{~m}$ test chamber has been setup alongside a hydronic loop. As a consequence of the investigation, it is recommended that the total, convective, and radiative heat transfer coefficients could be assumed as 5.7 (for $\mathrm{T}_{\mathrm{op} 1.1}$ ) W/m $/ \mathrm{m}^{2} \mathrm{~K}, 0.1 \mathrm{~W} / \mathrm{m}^{2} \mathrm{~K}$, and $5.0 \mathrm{~W} / \mathrm{m}^{2} \mathrm{~K}$, respectively, for a radiant floor cooling system. Besides, it is indicated that the heat transfer coefficient values are overestimated, in the range of 10-30\%, with respect to the values which are commonly used in radiant floor heating and cooling applications. Authors also mention the importance of proper reference temperatures in determining heat transfer coefficients as Olesen et al. [4] and Causone et al. [7], have done. In consideration of radiant floor cooling, EN12645 [8] and REHVA guidebook [9] suggest that the total heat transfer coefficient can be accepted as $6.5 \mathrm{~W} / \mathrm{m}^{2} \mathrm{~K}$ and $7 \mathrm{~W} / \mathrm{m}^{2} \mathrm{~K}$, respectively. In addition to reference temperatures, another study related to designing and dimensioning embedded radiant systems has been conducted by Olesen et al. [10]. By taking consideration of thermal comfort and building physics, it is recommended that minimum floor surface temperature for the peripheral and occupied zones is $19{ }^{\circ} \mathrm{C}$. The maximum surface temperature values for peripheral and occupied zones are suggested as $35^{\circ} \mathrm{C}$ and $29{ }^{\circ} \mathrm{C}$, respectively. In the case of floor cooling, authors recommend that $20{ }^{\circ} \mathrm{C}$ can be considered as an acceptable surface temperature for sedentary occupancy, while $18{ }^{\circ} \mathrm{C}$ is suitable for places with high activity.

In present study, the heat transfer characteristics of a radiant cooled floor under the experimental conditions as of 3 different supply water temperatures of $10^{\circ} \mathrm{C}, 15^{\circ} \mathrm{C}$, and $20^{\circ} \mathrm{C}$ with supply water flow rates as 0.056 and $0,125 \mathrm{~kg} / \mathrm{s}$ is investigated.

\section{Experimental Setup}

The test chamber has been set up in a laboratory, as shown in Figure 1, to study the heat transfer characteristics of an underfloor radiant cooling system. The properties of the materials that compose of the test chamber are summed up in Table 1.

Table 1: Properties of the materials of the enclosure 
2ND International Conference on Applied Research in

ENGINEERING, SCIENCE AND TECHNOLOGY

BRUSSELS, BELGIUM

\begin{tabular}{ccccc}
\hline & & $\begin{array}{c}\text { Thickness } \\
(\mathbf{m m})\end{array}$ & $\begin{array}{c}\text { Thermal conductuvity } \\
(\boldsymbol{\lambda}, \mathbf{W} / \mathbf{m K})\end{array}$ & $\begin{array}{c}\text { Water vapour diffusion } \\
\text { resistance }(\boldsymbol{\mu})\end{array}$ \\
\hline \multirow{3}{*}{$\begin{array}{l}\text { Walls \& } \\
\text { Ceiling }\end{array}$} & External plaster & 5 & 0.085 & $5-20$ \\
\cline { 2 - 5 } & Insulation & 50 & 0.035 & $90-100$ \\
\cline { 2 - 5 } & Aerated concrete & 150 & 0.39 & $5-10$ \\
\cline { 2 - 5 } Floor & Internal plaster & 5 & 0.87 & $5-10$ \\
\cline { 2 - 5 } & Aerated concrete & 150 & 0.39 & $90-100$ \\
\cline { 2 - 5 } & Insulation & 30 & 0.032 & $15-35$ \\
\cline { 2 - 5 } & Screed & 20 & 1.4 & 50 \\
\hline
\end{tabular}

Figure 1 (a-e) and Figure 2 (a-b) show the schematic representation and construction stages of the test chamber with pipe distribution of the radiant floor cooling system and the arrangement of thermocouples on radiant surfaces of the test chamber, respectively.

Figure 3 demonstrates the cold supply water line delivered to the hydronic circuits embedded in surfaces of the test room, additionally thirty-four $\mathrm{T}$ type thermocouples are installed to measure temperatures of the surfaces. The measured data are recorded after the system has come to steady-state conditions with homogenous temperature distribution on radiant surfaces.

Two calibrated PT100 type sensors are used to measure the supply water inlet and outlet temperatures. In order to determine the total heat transfer through the radiant system the supply water temperatures are measured just before and after the identified cooled floor section. While different supply water mass flow rates of $0.056 \mathrm{~kg} / \mathrm{s}$ and $0.125 \mathrm{~kg} / \mathrm{s}$ are applied, three different supply water temperatures are implemented as 10,15 and $20^{\circ} \mathrm{C}$. After the system has reached to the steady state conditions which takes approximately 6-7 hours, the data has collected via a PLC device that records the measurements in every 5 minutes. 
2ND International Conference on Applied Research in

ENGINEERING, SCIENCE AND TECHNOLOGY

5 - 7 JUNE, $2019 \quad$ BRUSSELS, BELGIUM

Figure 1: Schematic illustration of the test room

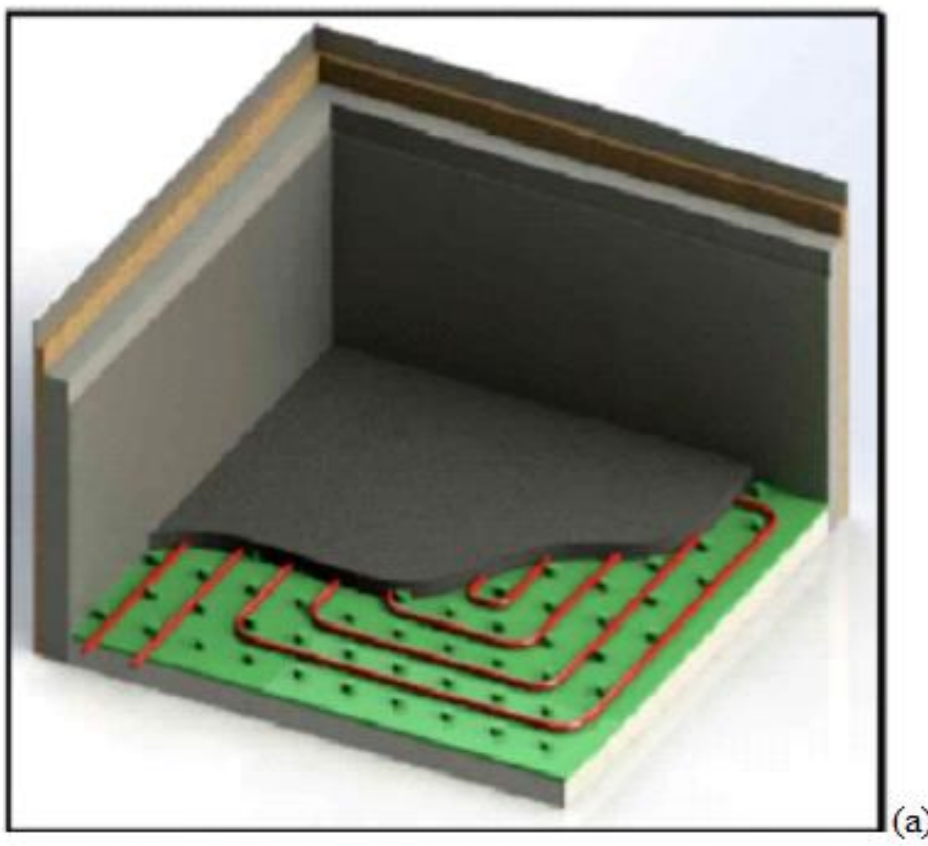

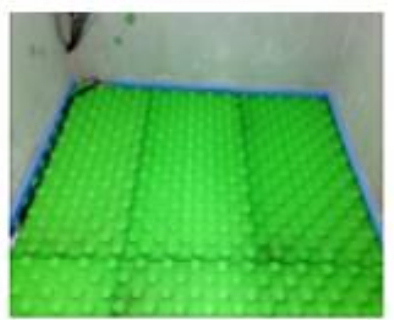

(b)

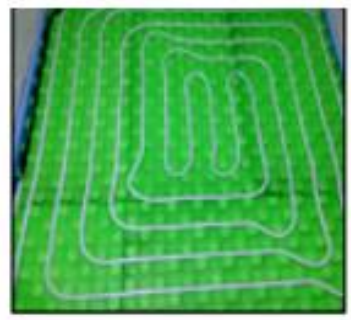

(c)

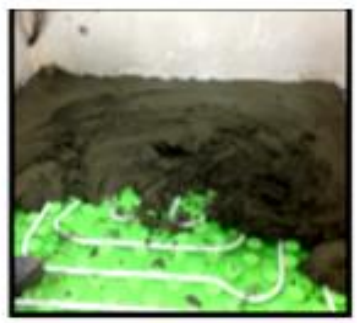

(d)

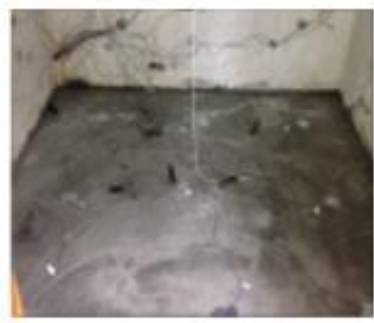

(e)

Figure 2: The pipe arrangement in the test room (a), the thermocouple distribution (b) 
2ND International Conference on Applied Research in ENGINEERING, SCIENCE AND TECHNOLOGY
5 - 7 JUNE, 2019
BRUSSELS, BELGIUM

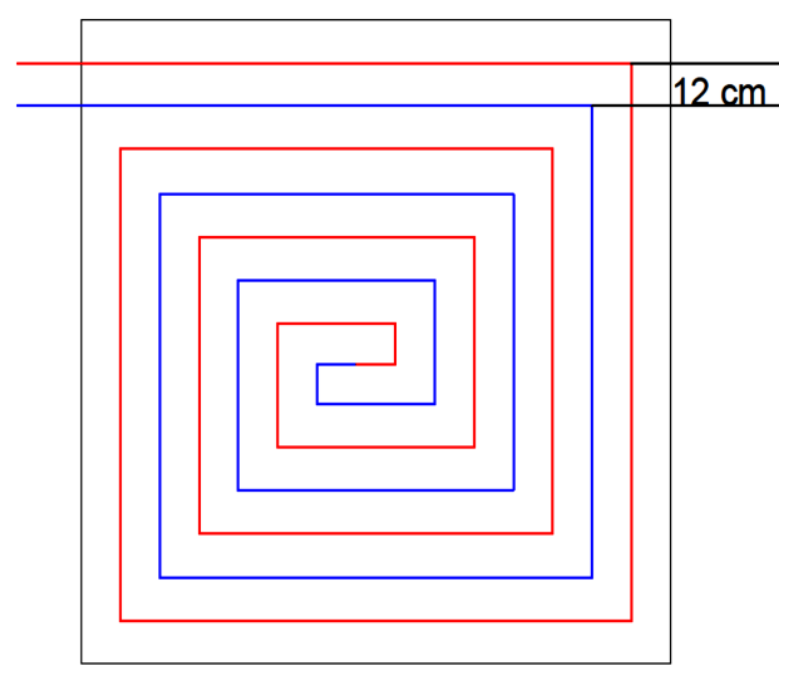

(a)

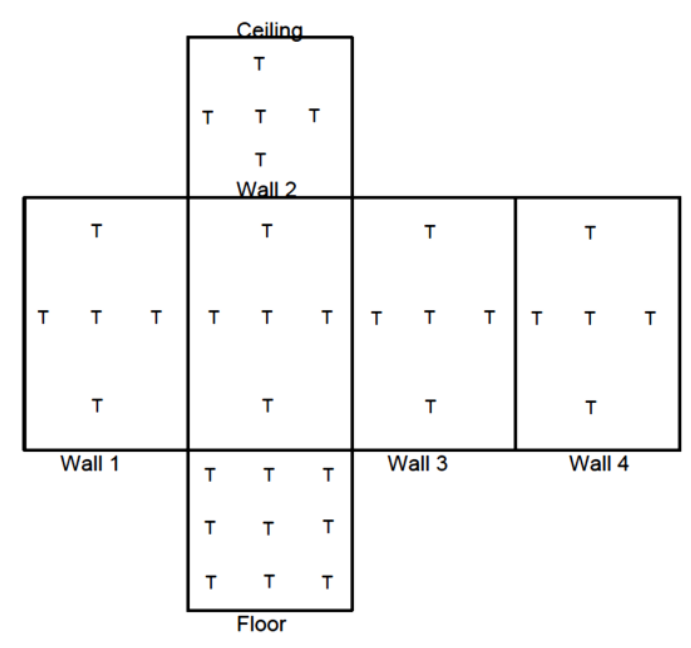

(b) 
2ND International Conference on Applied Research in ENGINEERING, SCIENCE AND TECHNOLOGY

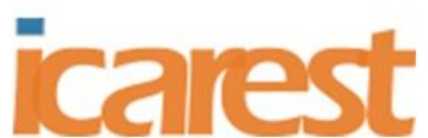

5 - 7 JUNE, 2019

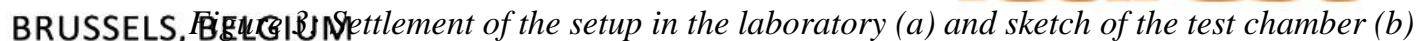

1. Heat storage water tank 2. Heat exchanger 3. Valve 4. Pump 5. Water supplier 6. Flow meter 7. PT100-hot-line 8. PT100-cold line 9. Pipes 10. Test chamber

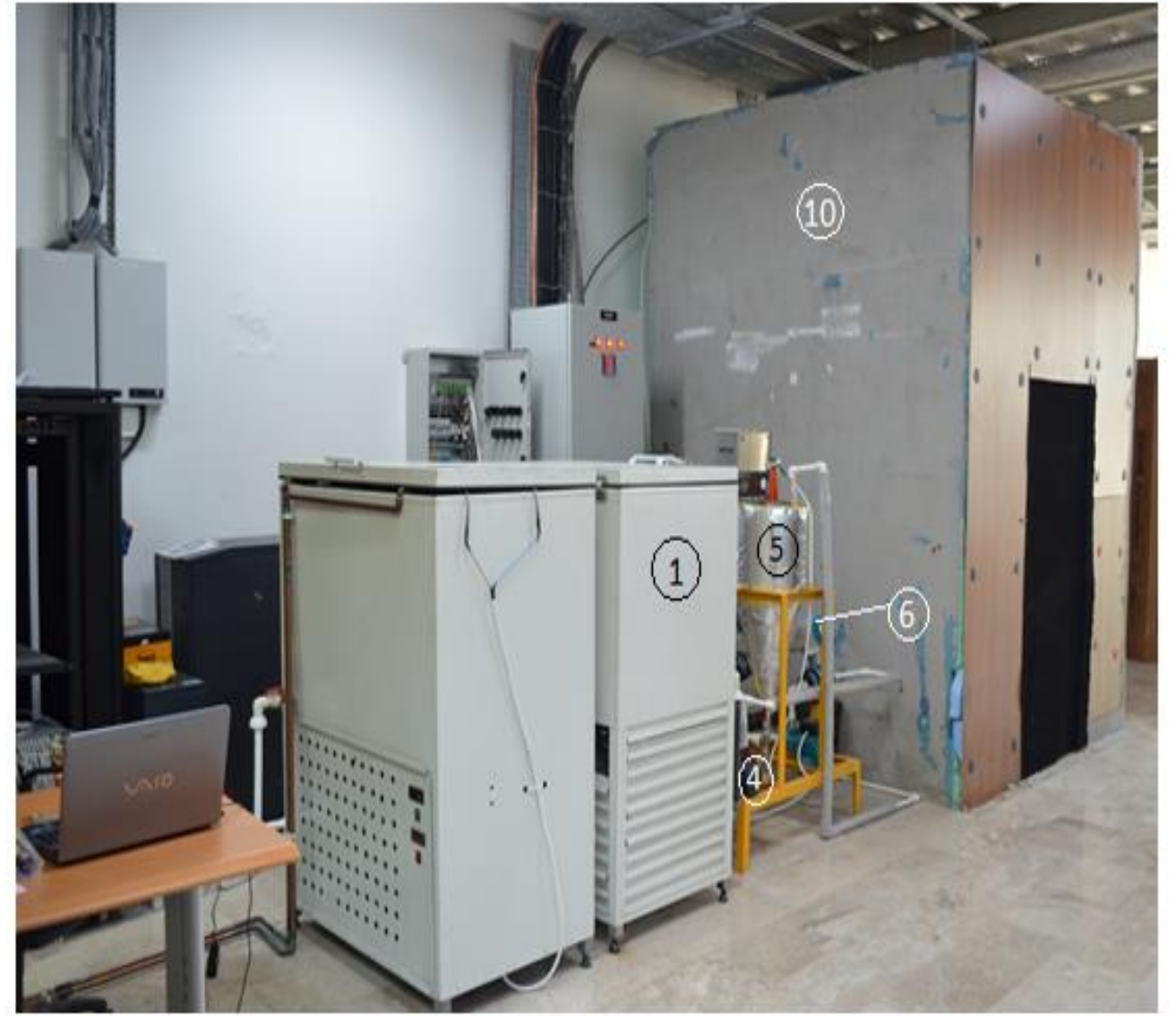

a)

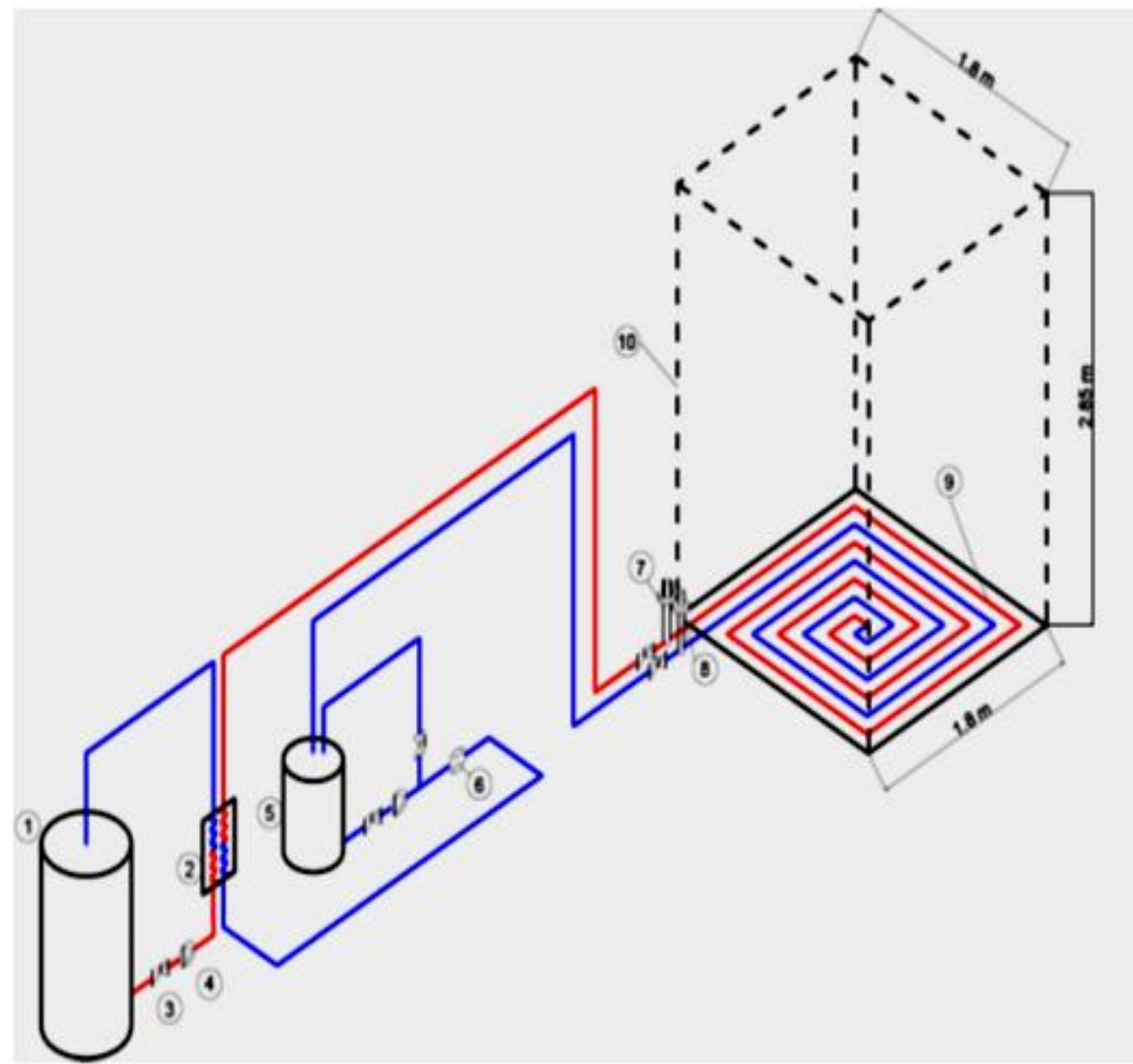

b) 
2ND International Conference on Applied Research in

ENGINEERING, SCIENCE AND TECHNOLOGY

5 - 7 JUNE, 2019

BRUSSELS, BELGIUM

\section{Calculation Process}

In this part, the calculation methodology of heat transfer characteristics of the radiant cooled floor system is described. The total heat transfer rate is calculated by Eq. (1) and here the temperature difference is the difference between the supply water inlet and outlet temperature of cooling circuit. Than the total heat transfer rate can be given as the sum of the radiation and convection heat transfer as in Eq. (2).

$$
\begin{aligned}
& \dot{Q}_{t}=\dot{m}_{w} c_{p}\left(T_{s}-T_{r}\right) \\
& \dot{Q}_{t}=\dot{Q}_{r}+\dot{Q}_{c}
\end{aligned}
$$

The proper reference temperatures are acquired from the study of Causone et al. [7] and shown in Table 2.

Table 2: Selected reference temperatures

\begin{tabular}{ccc}
\hline Heat transfer coefficient & Reference temperature $\left(\mathbf{T}_{\text {ref }}\right)$ & Temperature difference \\
\hline$h_{c}$ & $T_{a 1.1}, T_{a 1.4}$ & $T_{\text {ref }}-T_{f}$ \\
\hline$h_{r}$ & AUST & $T_{\text {ref }}-T_{f}$ \\
\hline$h_{t}$ & $T_{\text {op } 1.4}$ & $T_{\text {ref }}-T_{f}$ \\
\hline
\end{tabular}

Source: (Causone et al. [7])

Then, the total heat transfer coefficient between test chamber and radiant floor is calculated via Eq. (4).

$$
h_{t}=\frac{\dot{Q}_{t}}{A \cdot\left(T_{f}-T_{o p}\right)}
$$

In order to determine the radiant heat transfer coefficient the following equations as Eqs. $(5,6,7,8)$ can be implemented as in the relevant literature $[6,7,11$, and 12].

$$
\begin{aligned}
A U S T & =\sqrt[4]{\sum_{j=1}^{n}\left(F_{S-j} T_{j}^{4}\right)} \\
F \varepsilon_{s-j} & =\frac{1}{\left[\frac{1-\varepsilon_{S}}{\varepsilon_{S}}\right]+\left(\frac{1}{F_{S-j}}\right)+\left(\frac{A_{s}}{A j}\right)\left[\left(\frac{1-\varepsilon_{j}}{\varepsilon_{j}}\right)\right]} \\
q_{r} & =\sigma \sum_{j=1}^{n} F \varepsilon_{S-j}\left(T_{s}^{4}-T_{j}^{4}\right) \\
h_{r} & =\frac{\sigma \sum_{j=1}^{n} F \varepsilon_{s-j}\left(T_{s}^{4}-T_{j}^{4}\right)}{A U S T-T_{f}}
\end{aligned}
$$


2ND International Conference on Applied Research in

ENGINEERING, SCIENCE AND TECHNOLOGY

BRUSSELS, BELGIUM

The convective heat flux can be obtained via Eq. (9) and it means that it can be calculated by the extracting the radiant heat flux from the total heat flux.

$$
\dot{q}_{c}=\dot{q}_{t}-\dot{q}_{r}
$$

Finally, the convective heat transfer coefficient between radiant floor surface and room air is defined by Eq. (10) with the selected reference temperature of the air temperature at the middle of the test chamber.

$$
h_{c}=\frac{\dot{q_{c}}}{\left(T_{f}-T_{a}\right)}
$$

\section{Results and Discussion}

The present experimental study is aimed to investigate the heat fluxes from a cooled radiant floor system, while finding heat transfer characteristics regarding to radiation, convection, and total. Detailed results of the experimental measurements with the calculations based on the analyses is given in Table 3. As it can be seen from this table, the experiments have been performed at underfloor hydronic circuit mass flow rates of $0.056 \mathrm{~kg} / \mathrm{s}$ and 0.125 $\mathrm{kg} / \mathrm{s}$ with supply water temperatures as 10,15 , and $20{ }^{\circ} \mathrm{C}$.

\begin{tabular}{|c|c|c|c|c|c|c|c|c|c|c|c|c|}
\hline \multicolumn{5}{|c|}{ Measured Values } & \multicolumn{8}{|c|}{ Calculated Values } \\
\hline $\begin{array}{l}\mathbf{m}_{\mathbf{w}} \\
{[\mathrm{kg} /} \\
\mathrm{s}]\end{array}$ & $\begin{array}{l}\mathrm{T}_{\mathrm{f}} \\
{\left[{ }^{\circ} \mathrm{C}\right]}\end{array}$ & $\begin{array}{l}\mathrm{T}_{\mathrm{c}} \\
{\left[{ }^{\circ} \mathrm{C}\right]}\end{array}$ & $\begin{array}{l}\mathrm{T}_{\mathrm{s}} \\
{\left[{ }^{\circ} \mathrm{C}\right]}\end{array}$ & $\begin{array}{l}\mathrm{T}_{\mathrm{a}} \\
1.4 \mathrm{~m} \\
{\left[{ }^{\circ} \mathrm{C}\right]}\end{array}$ & $\begin{array}{l}\mathrm{q}_{\mathrm{t}} \\
{[\mathrm{W} / \mathrm{m}} \\
\left.{ }_{2}\right]\end{array}$ & $\begin{array}{l}\mathrm{q}_{\mathrm{r}} \\
{\left[\mathrm{W} / \mathrm{m}^{2}\right]}\end{array}$ & $\begin{array}{l}\mathrm{q}_{\mathrm{c}} \\
{[\mathrm{W} / \mathrm{m}} \\
2]\end{array}$ & $\begin{array}{l}\mathrm{T}_{\text {op. }} \\
1.4 \mathrm{~m} \\
{\left[{ }^{\circ} \mathrm{C}\right]}\end{array}$ & $\begin{array}{l}\text { AUST } \\
{\left[{ }^{\circ} \mathrm{C}\right]}\end{array}$ & $\begin{array}{c}\mathrm{h}_{\mathrm{t}} \\
{\left[\mathrm{W} / \mathrm{m}^{2}\right.} \\
\mathrm{K}]\end{array}$ & $\begin{array}{c}\mathrm{h}_{\mathrm{c}} \\
{\left[\mathrm{W} / \mathrm{m}^{2} \mathrm{~K}\right.} \\
]\end{array}$ & $\begin{array}{c}\mathrm{h}_{\mathrm{r}} \\
{[\mathrm{W} / \mathrm{m}} \\
\left.{ }^{2} \mathrm{~K}\right]\end{array}$ \\
\hline \multirow{3}{*}{$\stackrel{0}{\stackrel{0}{0}}$} & 12.80 & 22.92 & 10.0 & 22.5 & 54.89 & 49.68 & 5.21 & 22.08 & 22.82 & 5.91 & 0.53 & 4.96 \\
\hline & 16.81 & 23.90 & 15.0 & 23.6 & 40.13 & 35.61 & 4.51 & 23.31 & 23.81 & 6.18 & 0.66 & 5.09 \\
\hline & 20.76 & 24.34 & 20.0 & 24.2 & 20.32 & 18.34 & 1.98 & 24.03 & 24.29 & 6.21 & 0.57 & 5.20 \\
\hline \multirow{3}{*}{$\stackrel{\stackrel{1}{7}}{\frac{1}{9}}$} & 13.06 & 22.70 & 10.0 & 22.3 & 52.37 & 47.79 & 4.58 & 21.94 & 22.69 & 5.90 & 0.49 & 4.96 \\
\hline & 17.19 & 24.04 & 15.0 & 23.8 & 39.02 & 35.18 & 3.84 & 23.54 & 24.09 & 6.15 & 0.58 & 5.10 \\
\hline & 21.01 & 24.25 & 20.0 & 24.1 & 18.71 & 17.07 & 1.64 & 24.00 & 24.29 & 6.26 & 0.53 & 5.20 \\
\hline
\end{tabular}

Table 3: Measured and calculated values of heat transfer characteristics of the radiant cooled floor system

\subsection{Heat fluxes}

Figures 4 demonstrates the heat fluxes for the radiant cooled system with respect to convective, radiative, and total heat fluxes. It is noticeable from the figures that with growing values of temperature difference pertaining to radiative and total heat fluxes, these values increase. However, since air particles contacting with cool surface of the underfloor cooling surface stay beside over the floor, no remarkable air movement occurs, and hence much lower convective heat fluxes are obtained compared to radiative heat fluxes, and almost an unchanging trend with temperature difference $\left(T_{a}, 1.4 m-T_{f}\right)$ is observed. The convective heat fluxes varies in the range of $1.6-5.21 \mathrm{~W} / \mathrm{m}^{2}$, while due to being the dominant heat transfer mechanisms for a radiant floor cooling system, the radiative heat fluxes are in the range of 17.07 
2ND International Conference on Applied Research in

ENGINEERING, SCIENCE AND TECHNOLOGY

5 - 7 JUNE, 2019

BRUSSELS, BELGIUM

- $49.68 \mathrm{~W} / \mathrm{m}^{2}$. As the total heat flux is considered as the summation of both of the values of radiative and convective, it is given in the range of $18.71-54.89 \mathrm{~W} / \mathrm{m}^{2}$.

Additionally, according to the experiments carried out, Figure 5 illustrates the change of floor surface temperature. It is noticed that when the supply water temperature is changed from $10{ }^{\circ} \mathrm{C}$ to $20^{\circ} \mathrm{C}$, the floor surface temperature shows unchanging trend with respect to the different values of implemented mass flow rates.

Figure 4: The variation of convective, radiative, and total heat fluxes of a radiant cooled floor system

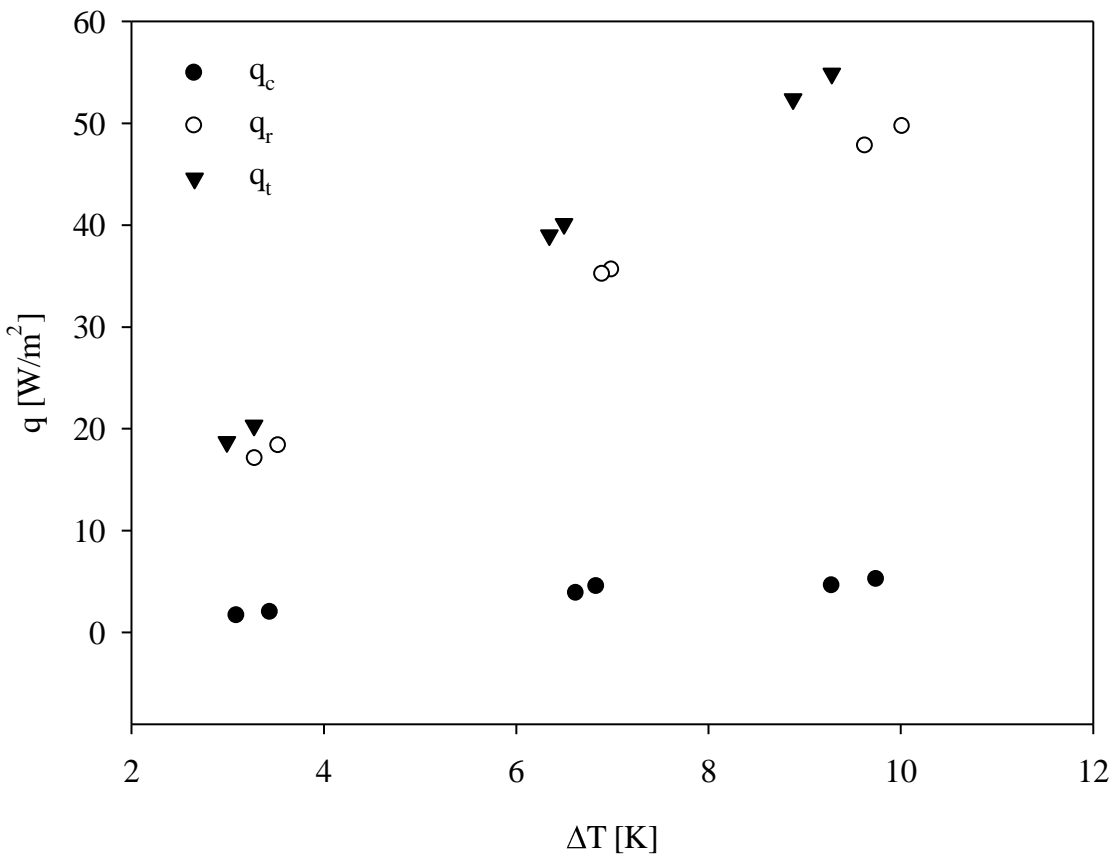

Figure 5: The effect of water flow rate on floor surface temperature for the radiant floor cooling system 
2ND International Conference on Applied Research in

ENGINEERING, SCIENCE AND TECHNOLOGY

5 - 7 JUNE, 2019

BRUSSELS, BELGIUM

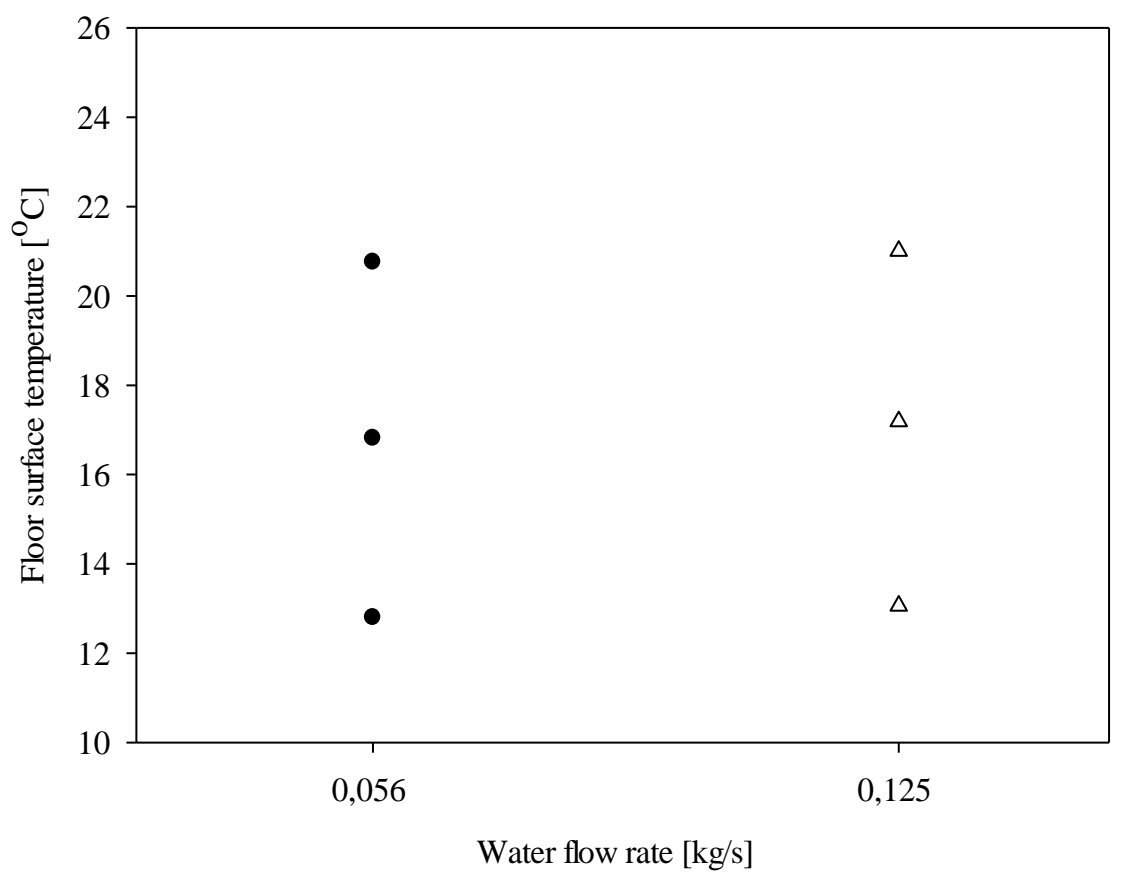

\subsection{Heat transfer coefficients}

Figure 6 demonstrates the variation of convective, radiative, and total heat transfer coefficients with regard to temperature differences. It is clear from Table 3 that almost an unchanging tendency is observed for radiative heat transfer coefficient as $5.0-5.2 \mathrm{~W} / \mathrm{m}^{2} \mathrm{~K}$. Moreover, low convective heat transfer data can be seen from Figures 6 and Table 3 that can be accounted for the low air movement. Consequently, radiation is the determinant phenomenon on total heat transfer coefficient with a mean total heat transfer coefficient value of $6.1 \mathrm{~W} / \mathrm{m}^{2} \mathrm{~K}$.

Figure 6: The tendency of all heat transfer coefficients with respect to temperature differences 
2ND International Conference on Applied Research in

ENGINEERING, SCIENCE AND TECHNOLOGY

5 - 7 JUNE, 2019

BRUSSELS, BELGIUM

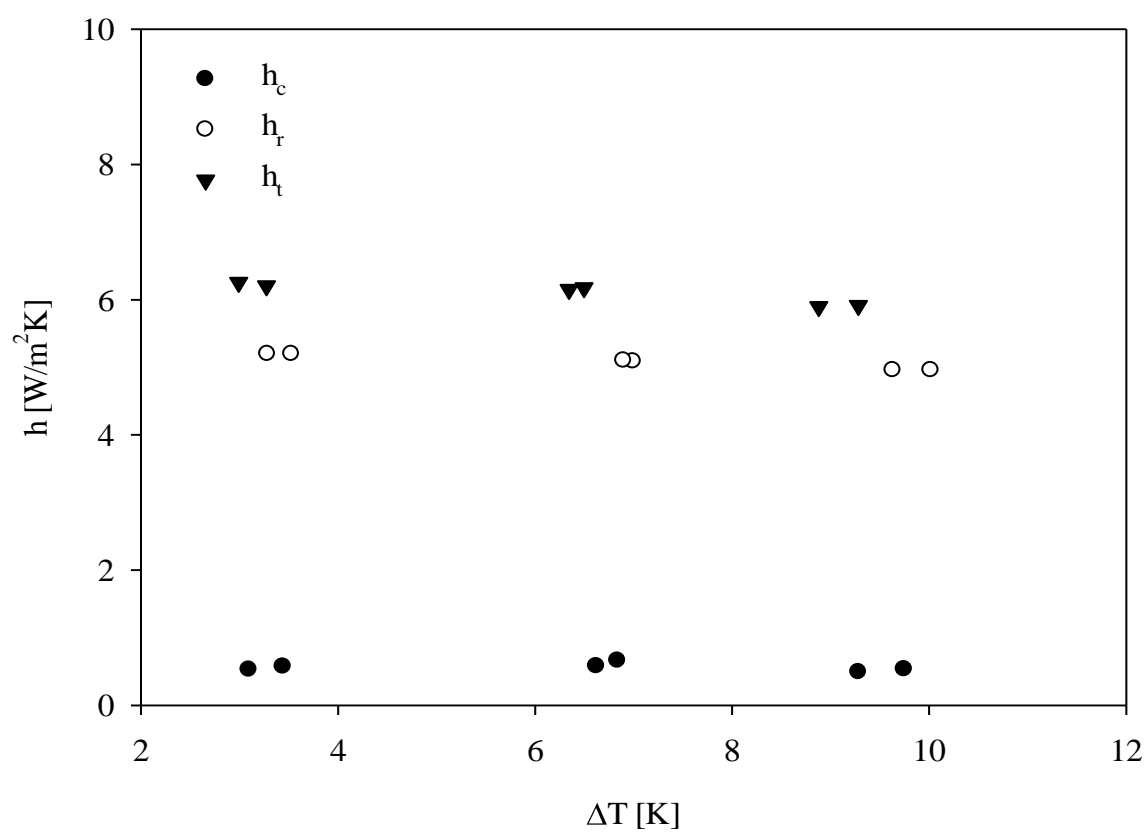

\subsection{Validation of results with literature}

Figures 7 (a-d) illustrate the comparison of the findings of this investigation with those of some other researchers and international standards such as Min et al. [13], Awbi and Hatton [14], Cholewa et al. [6], and BS EN 15377 - 1 [5]. Figure 7a contrasts the data through the present work with the outcomes acquired via the correlations explored by Min et al. [13] and Awbi and Hatton [14]. It is observed that results obtained using the correlation of Min et al. [13] gives lowest ones compared to those of Awbi and Hatton [14], and the present study. One can notice from the figure that the use of the equation by Awbi and Hatton [14] gives closer results than those by Min et al. [13]. Additionally, a scattered distribution of data from the present investigation is spotted in Figure 7a. This can be attributed to the fact that experimental errors mentioned in the previous paragraph to be assigned into convection data, since, radiation results to be calculated via a theoretical method. Nevertheless, the present work concludes a mean convective heat transfer coefficient result of $0.6 \mathrm{~W} / \mathrm{m}^{2} \mathrm{~K}$, as the results gained through the correlations of Awbi and Hatton [14], and Min et al. [13] are $0.5 \mathrm{~W} / \mathrm{m}^{2} \mathrm{~K}$, and $0.2 \mathrm{~W} / \mathrm{m}^{2} \mathrm{~K}$, respectively. Underlying reason for this similarity is that in both applications air pattern demonstrates very little air movements in the enclosure.

Figure $7 \mathrm{~b}$ compares the radiative heat flux data through radiant cooled floor with the outcomes of Cholewa et al. [6]. It can clearly be spotted that the outcomes of both works come after the same trend line, and validates each other. Figure 7c contrasts the convective heat flux data of this work and those of Cholewa et al. [6]. One can notice from the figure that Cholewa et al. [6] give slightly lower convective heat flux data at the same temperature difference $\left(\mathrm{T}_{\mathrm{a}}\right.$, $1.4 \mathrm{~m}-\mathrm{T}_{\mathrm{f}}$ ) values. On the other hand, it is understandable that the results of this study increases with growing values of $\left(T_{a}, 1.4 m-T_{f}\right)$, because of increasing air movements over the radiant cooled floor. Figure $7 \mathrm{~d}$ validates the total heat flux outcomes of this investigation by those of Cholewa et al. [6], and correlation of BS EN 15377-1 [5]. All three studies including the present investigation pursue almost the same trend line in terms of total heat flux through a radiant 
2ND International Conference on Applied Research in

ENGINEERING, SCIENCE AND TECHNOLOGY

5 - 7 JUNE, 2019

BRUSSELS, BELGIUM

cooled floor, while in all three investigations operative temperature has been assumed as the reference one for total heat flux values. Very slight deviations between trend lines can be caused by thermal boundary conditions of this study implemented to simulate heat gains, the point in the room air temperature is measured, possible slight differences in surface emissivity, and unavoidable experimental errors elaborated in previous lines.

Figure 7: Evaluation of (a) convective heat transfer coefficient, (b) radiative heat flux, (c) convective heat flux, and $(d)$ total heat flux of this study with literature values
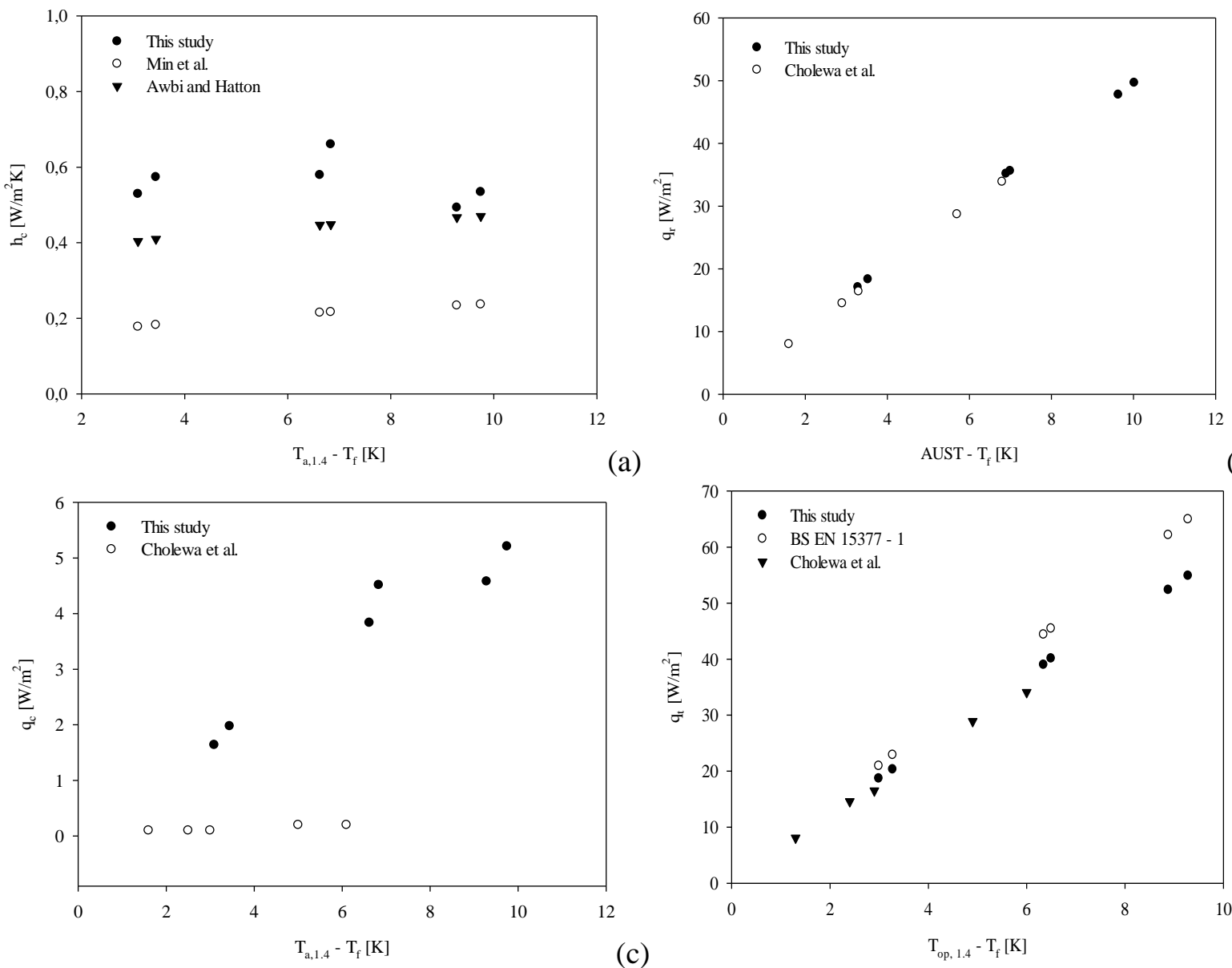

(b)

Figure 8: The proportion of radiative and convective heat transfer rate in total heat transfer rate 
2ND International Conference on Applied Research in

ENGINEERING, SCIENCE AND TECHNOLOGY

5 - 7 JUNE, 2019

BRUSSELS, BELGIUM

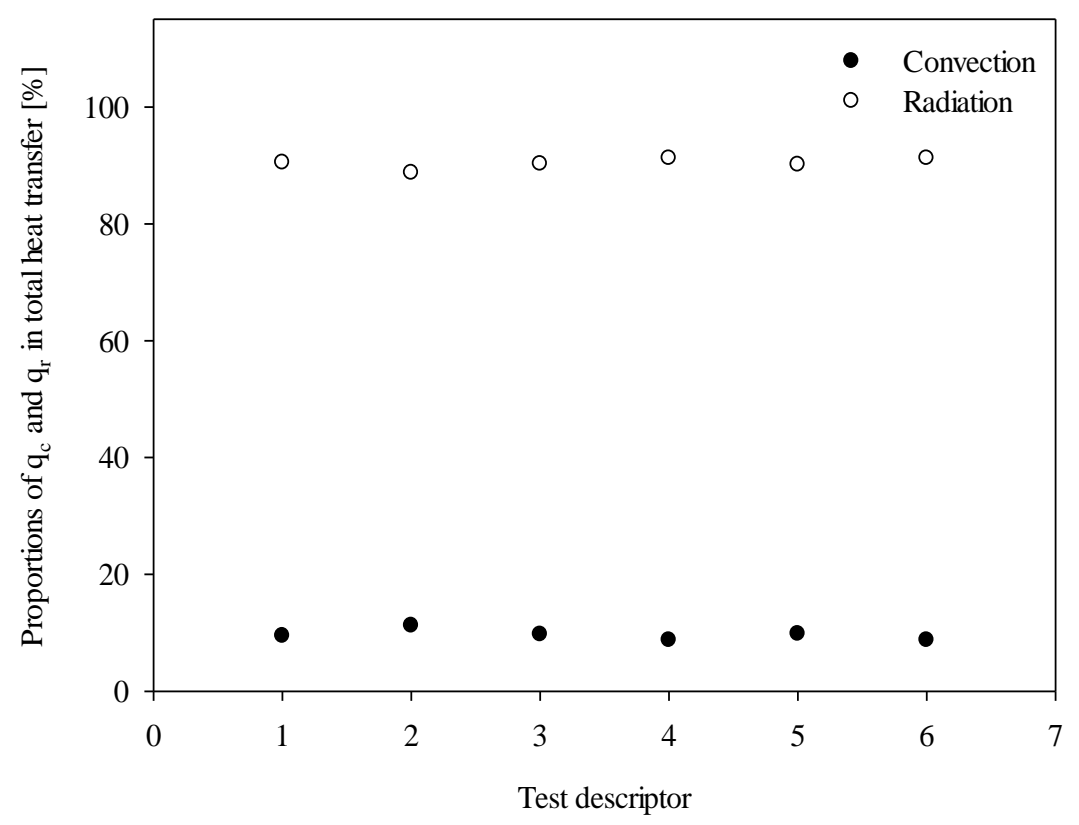

Figure 8 shows quantities of radiation and convection in total heat transfer in percentile. In accordance with the figure, the radiative heat transfer has formed roughly $91 \%$ of total heat transfer rate through the cooled floor.

\section{Conclusion}

In this work, convective and radiative heat fluxes along with heat transfer coefficients over a radiant cooled underfloor system are analyzed. To achieve this aim, definite mass flow rates and surface temperatures are selected, and applied into the hydronic circuits embedded in to the surfaces of an experimental chamber. The summary of results are given in the following statements:

a. The radiative, convective, and total heat transfer coefficient ranges of $4.4-5.5 \mathrm{~W} / \mathrm{m}^{2} \mathrm{~K}$, $0.4-0.7 \mathrm{~W} / \mathrm{m}^{2} \mathrm{~K}$, and $5.9-6.2 \mathrm{~W} / \mathrm{m}^{2} \mathrm{~K}$, respectively. Additionally, the radiative and total heat transfer data show close tendencies with commonly referenced studies. It has been concluded that average radiative, convective, and total heat transfer coefficient values of $5.1 \mathrm{~W} / \mathrm{m}^{2} \mathrm{~K}, 0.6 \mathrm{~W} / \mathrm{m}^{2} \mathrm{~K}$, and $6.1 \mathrm{~W} / \mathrm{m}^{2} \mathrm{~K}$ can be proposed, respectively.

b. The trend of convective heat transfer data is compatible with that in relevant literature, nevertheless, the convective data of this investigation are slightly above the prevalently used comparison sources by 5-20\%.

c. It is concluded that the predominant heat transfer mechanism pertaining to a hydronic radiant underfloor cooling system is radiation with a mean ratio of $91 \%$ in total realized heat transfer.

\section{Nomenclature}

A Surface area (m2)

AUST Average unheated surface temperature $\left({ }^{\circ} \mathrm{C}\right)$

cp Specific heat $(\mathrm{J} / \mathrm{kgK})$ 
2ND International Conference on Applied Research in

ENGINEERING, SCIENCE AND TECHNOLOGY

BRUSSELS, BELGIUM

Fs- $j \quad$ View factor between the radiant surface and $j$ surfaces

hc Convective heat transfer coefficient $(\mathrm{W} / \mathrm{m} 2 \mathrm{~K})$

$\mathrm{hr} \quad$ Radiative heat transfer coefficient (W/m2K)

ht Total heat transfer coefficient $(\mathrm{W} / \mathrm{m} 2 \mathrm{~K})$

mw Mass flow rate $(\mathrm{kg} / \mathrm{s})$

Qc Convective heat transfer (W)

Qr Radiative heat transfer (W)

qc Convective heat flux (W/m2)

qr Radiative heat flux $(\mathrm{W} / \mathrm{m} 2)$

qt Total heat flux $(\mathrm{W} / \mathrm{m} 2)$

Ta Air temperature $\left({ }^{\circ} \mathrm{C}\right)$

Top Operative temperature $\left({ }^{\circ} \mathrm{C}\right)$

Tf Cooled floor temperature $\left({ }^{\circ} \mathrm{C}\right)$

Ts Supply water temperature $\left({ }^{\circ} \mathrm{C}\right)$

Tc Ceiling temperature $\left({ }^{\circ} \mathrm{C}\right)$

Tw Wall temperature $\left({ }^{\circ} \mathrm{C}\right)$

$\Delta \mathrm{T} \quad$ Temperature difference between radiant heated floor and reference temperature $\left({ }^{\circ} \mathrm{C}\right)$

$\varepsilon \quad$ Surface emissivity

$\sigma \quad$ Stefan-Boltzmann constant $(\mathrm{W} / \mathrm{m} 2 \mathrm{~K} 4)$

$\lambda \quad$ Thermal conductivity $(\mathrm{W} / \mathrm{mK})$

$\mu \quad$ Water vapour diffusion resistance

\section{References}

[1] Zhao, K., Liu, X. H. and Jiang, Y. (2014). On-site measured performance of a radiant floor cooling/heating system in Xi'an Xianyang International Airport. Solar Energy, 108, 274-286.

[2] Zhao, K., Liu, X. H. and Jiang, Y. (2013). Application of radiant floor cooling in a large open space building with high-intensity solar radiation. Energy and buildings, 66, 246-257.

[3] Pantelic, J., Schiavon, S., Ning, B., Burdakis, E., Raftery, P. and Bauman, F. (2018). Full scale laboratory experiment on the cooling capacity of a radiant floor system. Energy and Buildings, 170, 134-144.

[4] Olesen, B. W., Bonnefoi, F., Michel, E. and Carli, M. D. (2000). Heat exchange coefficient between floor surface and space by floor cooling--Theory or a question of definition. DF Liedelt Velta, Norderstedt (DE).

[5] BS EN 15377-1, Heating systems in buildings - Design of embedded water based surface heating and cooling systems: Determination of the design heating and cooling capacity, 2008.

[6] Cholewa, T., Rosiński, M., Spik, Z., Dudzińska, M. R. and Siuta-Olcha, A. (2013). On the heat transfer coefficients between heated/cooled radiant floor and room. Energy and Buildings, 66, 599-606.

[7] Causone, F., Corgnati, S. P., Filippi, M. and Olesen, B. W. (2009). Experimental evaluation of heat transfer coefficients between radiant ceiling and room. Energy and buildings, 41(6), 622-628. 
2ND International Conference on Applied Research in

ENGINEERING, SCIENCE AND TECHNOLOGY

5 - 7 JUNE, 2019

BRUSSELS, BELGIUM

[8] EN 1264-5, (2008). Water based surface embedded heating and cooling systems, in: Part 5: Heating and Cooling Surfaces Embedded in Floors, Ceilings and Walls - Determination of the Thermal Output, CEN.

[9] J. Babiak and B.W. Olesen, D. Petras Low Temperature Heating and High Temperature Cooling: Rehva Guidebook No.7 Rehva, Brussels (2009)

[10] Olesen, B. W., Koschenz, M. and Johansson, C. (2003). New European standard proposal for design and dimensioning of embedded radiant surface heating and cooling systems. ASHRAE Transactions, 109, 656.

[11] Acikgoz, O., Karakoyun, Y., Yumurtacı, Z., Dukhan, N. and Dalkılıç, A. S. (2019). Realistic experimental heat transfer characteristics of radiant floor heating using sidewalls as heat sinks. Energy and Buildings, 183, 515-526.

[12] Cholewa, T., Anasiewicz, R., Siuta-Olcha, A. and Skwarczynski, M. A. (2017). On the heat transfer coefficients between heated/cooled radiant ceiling and room. Applied Thermal Engineering, 117, 76- 84.

[13] Min, T. C., Schutrum, L. F., Parmelee, G. V. and Vouris, J. D. (1956). Natural convection and radiation in a panel heated room. ASHRAE Transactions, 62(1), 337-358.

[14] Awbi, H. B. and Hatton, A. (1999). Natural convection from heated room surfaces. Energy and buildings, 30(3), 233-244. 